Research paper

\title{
Nitrogen-containing ecdysteroid derivatives vs. multi-drug resistance in cancer: Preparation and antitumor activity of oximes, oxime ethers and a lactam
}

\author{
Máté Vágvölgyi a ${ }^{\text {, Ana Martins }}{ }^{\mathrm{b}, 1}$, Ágnes Kulmány ${ }^{\mathrm{c}}$, István Zupkó ${ }^{\mathrm{c}}$, Tamás Gáti ${ }^{\mathrm{d}}$, \\ András Simon ${ }^{\mathrm{e}}$, Gábor Tóth ${ }^{\mathrm{e}}$, Attila Hunyadi ${ }^{\mathrm{a}}{ }^{\mathrm{f}, *}$ * \\ a Institute of Pharmacognosy, Faculty of Pharmacy, University of Szeged, Szeged, Hungary \\ b Department of Medical Microbiology and Immunobiology, Faculty of Medicine, University of Szeged, Szeged, Hungary \\ ${ }^{c}$ Institute of Pharmacodynamics and Biopharmacy, Faculty of Pharmacy, University of Szeged, Szeged, Hungary \\ d Servier Research Institute of Medicinal Chemistry (SRIMC), Budapest, Hungary \\ e NMR group, Department of Inorganic and Analytical Chemistry, University of Technology and Economics, Budapest, Hungary \\ ${ }^{\mathrm{f}}$ Interdisciplinary Centre for Natural Products, University of Szeged, Szeged, Hungary
}

\section{A R T I C L E I N F O}

\section{Article history:}

Received 27 October 2017

Received in revised form

8 December 2017

Accepted 9 December 2017

Available online 12 December 2017

\section{Keywords:}

Ecdysterone

Semi-synthesis

Beckmann-rearrangement

Chemotherapy

Adjuvant

ABCB1 transporter

P-glycoprotein

Efflux pump inhibitor

\begin{abstract}
A B S T R A C T
Multidrug resistance is a widespread problem among various diseases and cancer is no exception. We had previously described the chemo-sensitizing activity of ecdysteroid derivatives with low polarity on drug susceptible and multi-drug resistant (MDR) cancer cells. We have also shown that these molecules have a marked selectivity towards the MDR cells. Recent studies on the oximation of various steroid derivatives indicated remarkable increase in their antitumor activity, but there is no related bioactivity data on ecdysteroid oximes. In our present study, 13 novel ecdysteroid derivatives (oximes, oxime ethers and a lactam) and one known compound were synthesized from 20-hydroxyecdysone 2,3;20,22diacetonide and fully characterized by comprehensive NMR techniques revealing their complete ${ }^{1} \mathrm{H}$ and ${ }^{13} \mathrm{C}$ signal assignments. The compounds exerted moderate to strong in vitro antiproliferative activity on HeLa, SiHa, MCF-7 and MDA-MB-231 cell lines. Oxime and particularly oxime ether formation strongly increased their inhibitory activity on the efflux of rhodamine 123 by P-glycoprotein (P-gp), while the new ecdysteroid lactam did not interfere with the efflux function. All compounds exerted potent chemosensitizing activity towards doxorubicin on a mouse lymphoma cell line and on its MDR counterpart, and, on the latter, the lactam was found the most active. Because of its MDR-selective chemo-sensitizing activity with no functional effect on P-gp, this lactam is of high potential interest as a new lead for further antitumor studies.
\end{abstract}

() 2017 Elsevier Masson SAS. All rights reserved.

\section{Introduction}

Synthetic modification of steroidal compounds remains a promising strategy in the hunt for novel drug candidates since even minor changes in the substitution pattern of their chemical backbone may significantly modify specific bioactivities. Certain steroidal oximes and oxime ethers were shown to have antioxidant

\footnotetext{
* Corresponding author. Institute of Pharmacognosy, Faculty of Pharmacy, University of Szeged, Eötvös u. 6, H-6720 Szeged, Hungary.

E-mail address: hunyadi.a@pharm.u-szeged.hu (A. Hunyadi).

1 Current address: Synthetic Systems Biology Unit, Institute of Biochemistry, Biological Research Centre, Temesvári krt. 62, H-6726 Szeged, Hungary.
}

[1], antimicrobial [1], antineoplastic [2] or neuromuscular blocking [3] activities.

Currently, the antitumor activity of steroid oximes is by far the most deeply investigated and has recently attracted great scientific attention. For example, oximes and lactams of cholest-4-en-6-one were tested on two human cancer cell lines and were shown to have very high, tumor selective anticancer activity on HeLa cells [4]. Another study on the structure-activity relationships (SAR) of hydroxyiminosteroids bearing the oxime group on the steroid $A$ and/or B ring showed that a C-6 oxime function is preferential over a 6-keto group concerning in vitro cytotoxic activity of these type of compounds [5]. In a follow-up study on the same compounds, the importance of 3- and 6-hydroxy functions was highlighted [6]. 
Furthermore, a set of in vitro experiments on 63 novel estrone 16oximes and oxime ethers revealed two oximes as promising antiproliferative agents with selectivity towards HeLa cells; the compounds modulated cell cycle and induced apoptosis through caspase-3 [7]. In a most recent study, a series of steroidal oximes and lactams were described to possess significant in vitro antiproliferative activity, and a 6,23-dioxime derivative, obtained from diosgenin acetate, was identified to be the most effective [8]. Several further recent reports can be found in the literature where well-defined mechanistic changes could also be connected to the increase in the antiproliferative activity observed after introducing an oxime moiety into an oxo-compound. For example, a number of $\alpha, \beta$-unsaturated, cyclohexanone-based oximes showed greatly increased activity as compared to their parental oxo-compounds against $\mathrm{BRAF}^{\mathrm{V} 600 \mathrm{E}}$ (the most common mutation in the v-raf murine sarcoma viral oncogenes homolog B1, involved in carcinogenesis and cancer agressiveness) and/or epidermal growth factor receptor TK kinases (involved in cell proliferation, evasion of apoptosis and invasive capacity) [9], or focal adhesion kinase (FAK; involved in stimulating metastasis and tumor progression) [10]. These reports suggest that the preparation of oxime derivatives from ketosteroids, and particularly from those with an $\alpha, \beta$-enone moiety, should be a reasonable strategy to extend the chemical space towards new, potentially antitumor compounds.

Ecdysteroids are $\alpha, \beta$-unsaturated 6-ketosteroids that occur in a wide range of plant species; as analogs of the insect molting hormone ecdysone, these compounds possess several biological functions in the flora and the fauna [11,12]. Since the isolation of the most abundant ecdysteroid 20-hydroxyecdysone (20E), these compounds were reported to also exert various, beneficial bioactivities in mammals [13,14,15,16]. Additionally, our group revealed that relatively apolar ecdysteroids can strongly sensitize cancer cells to chemotherapeutics (i.e. "chemo-sensitizing" activity), and suggested 20-hydroxyecdysone 2,3;20,22-diacetonide (1) as a promising anticancer lead compound [17]. Interestingly, this sensitization towards various chemotherapeutics could be observed both on multi-drug resistant (MDR) and drug susceptible cancer cell lines [18]. After several further studies, exploring this particular anticancer activity of ecdysteroids, we now know that 1) apolar substituents on the 2,3-diol moiety are more important than those at positions 20 and 22 [19], and 2) an oxidative side-chain cleavage knocks out the inhibitory activity on the efflux function of the ABCB1 transporter (P-glycoprotein; P-gp) while maintaining MDR selective sensitizing activity towards doxorubicin [20]. Regarding semi-synthetic modifications accompanied by the inclusion of heteroatoms, a difluorinated derivative of 20E 2,3;20,22diacetonide was found to be a stronger P-gp inhibitor than its parental molecule (compound 1), while, surprisingly, MDR selectivity of the difluorinated compound was lower: it sensitized a P-gp expressing MDR cell line to doxorubicin similarly to its parental compound $\mathbf{1}$, and a stronger effect than that of $\mathbf{1}$ was observed on a non-MDR cell line [21]. The chemical structures of 20E and compound 1 are shown in Fig. 1.
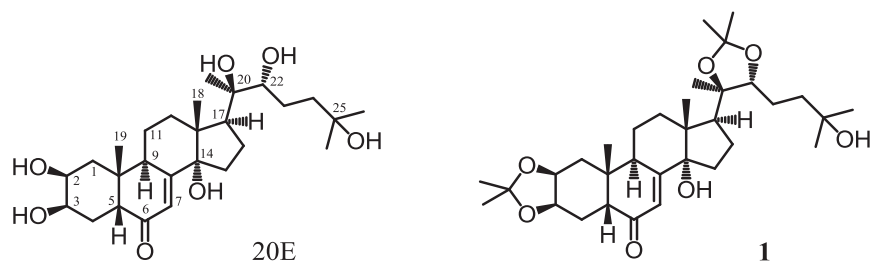

Fig. 1. Chemical structures of 20-hydroxyecdysone (20E) and 20-hydroxyecdysone 2,3;20,22-diacetonide (1).
Galyautdinov et al. have previously reported the successful preparation of several $(E / Z)$-isomeric ecdysteroid 6-oxime and some lactam derivatives [22]. Considering the above mentioned antitumor potential of steroidal oximes and the fact that no studies are available on the bioactivity of ecdysteroid oximes or lactams, the aim of the present work was to prepare a series of such compounds, and study their in vitro antitumor potential with a focus on their chemo-sensitizing activity.

\section{Results and discussions}

\subsection{Chemistry}

20-hydroxyecdysone 2,3; 20.22-diacetonide $\mathbf{1}$ and its 6-oxime and lactam derivatives were synthesized following previously published procedures [22,23]. Briefly, compound 1 was reacted with hydroxylamine or, aiming to prepare new oxime ethers, an alkoxylamine in pyridine at $70^{\circ} \mathrm{C}$. A total of 14 nitrogen-containing derivatives were prepared this way (Scheme 1).

Following each reaction, neutralization with $\mathrm{KOH}$ dissolved in anhydrous methanol was utilized with the aim of obtaining several different, structurally diverse and potentially bioactive products, including mixtures of 14,15-anhydro- and intact oxime derivatives: the oximes 2 and 3, and oxime ethers with different 6-O-alkyl substituents 5-15, respectively, were obtained through this method. Our results confirm previous observations that ecdysteroid 6-oximation can result in 3 different types of product mixtures depending on the neutralization procedure [22]: a mixture of 14,15anhydro (E/Z)-isomeric oxime pairs form if the reaction does not include a neutralization step; a 2-4 components mixture of both intact and $140 \mathrm{OH}$-eliminated derivatives is obtained if alkali dissolved in anhydrous methanol is added; and a mixture of intact $(E /$ $Z$ )-isomeric oxime pair with retained $14-\mathrm{OH}$ groups is obtained if the neutralizing alkali is dissolved in anhydrous ethanol.

A second transformation involving the Beckmannrearrangement of the $(6 E)$-oxime compound $\mathbf{2}$ was performed utilizing $p$-toluenesulfonyl chloride ( $\mathrm{TsCl}$ ) in acetone in the presence of sodium carbonate to obtain a new ecdysteroid derivative, compound 4, with a seven-membered lactam ring (Scheme 2). As expected, the (6Z)-oxime compound did not form the corresponding lactam but a tosylate was obtained (not presented, for more details see also reference [23]).

\subsection{Structure elucidation}

We have recently reported the structure elucidation and complete ${ }^{1} \mathrm{H}$ and ${ }^{13} \mathrm{C}$ signal assignment of a series of dioxolane derivatives of 20-hydroxyecdysone [19,20,21,24]. Here we discuss the complete ${ }^{1} \mathrm{H}$ and ${ }^{13} \mathrm{C}$ signal assignment of the corresponding 6 oxime and 6-oxime ether derivatives.

The structure and NMR signals of the products were assigned by comprehensive one- and two-dimensional NMR methods, such as ${ }^{1} \mathrm{H},{ }^{13} \mathrm{C}$, DEPTQ gradient-selected COSY, edited HSQC, HMBC, ROESY (Rotating frame Overhauser Enchancement Spectroscopy) spectra and 1D-selective variants thereof. It is worth mentioning that due to the molecular mass (500-700 Da) the signal/noise value of the selective ROE experiments strongly exceeds that of the selective NOEs.

To facilitate the comparison of NMR signals of structurally analogous hydrogen and carbon atoms of the starting compound $\mathbf{1}$ with those of the 6-oxime 2, and of its Beckmann rearranged product 4 and 6-oxime-ether derivatives 5-15, we applied the usual steroid numbering, and for the central atoms of the 2,3;20,22diacetonide moieties C-28 and C-29, respectively. The ${ }^{13} \mathrm{C}$ chemical shifts of compounds 1, 2 and 4-15 in methanol- $d_{4}$ are compiled in 


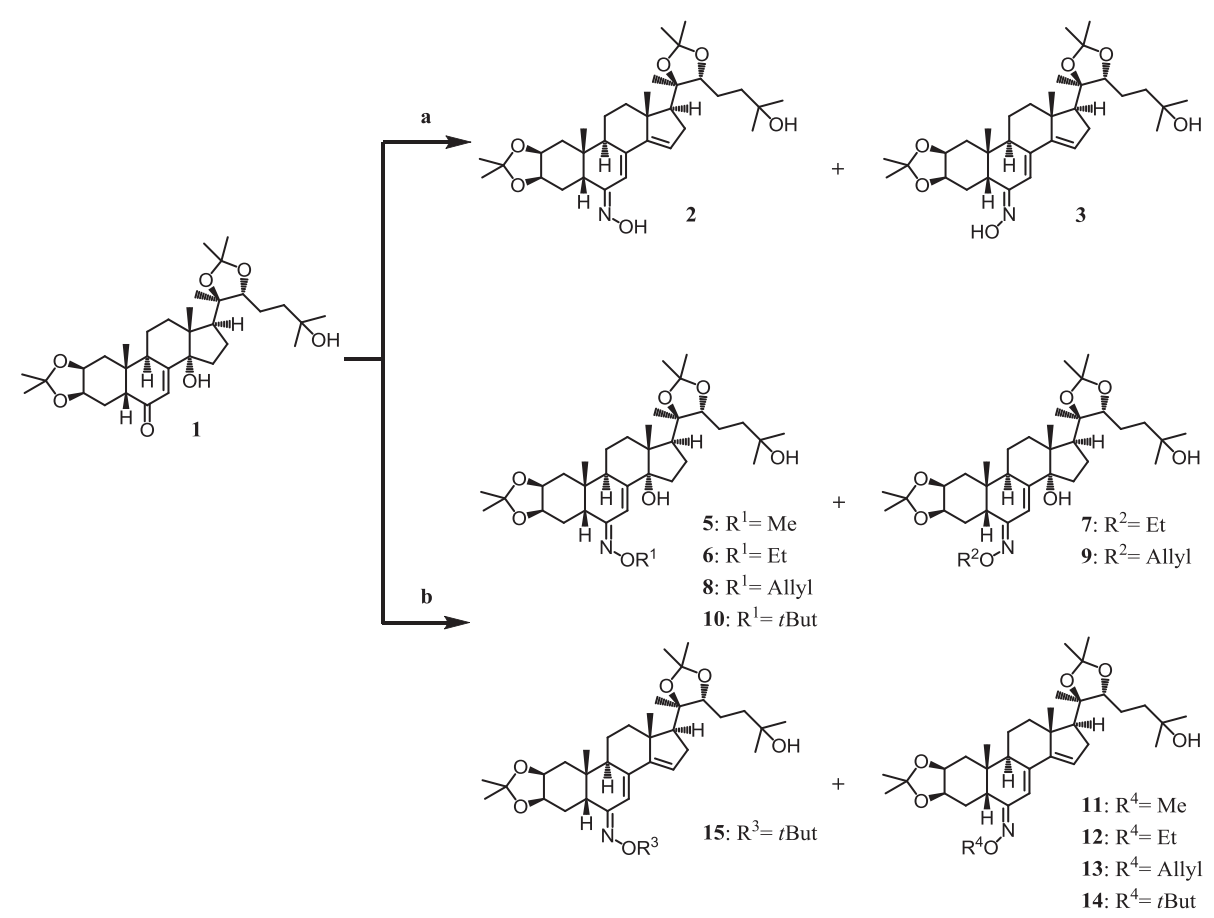

Scheme 1. Synthesis of oxime and oxime ether derivatives of 20-hydroxyecdysone 2,3;20,22-diacetonide.

Reagents and conditions: a) pyridine, $\mathrm{NH}_{2} \mathrm{OH} \cdot \mathrm{HCl}, 70{ }^{\circ} \mathrm{C}, 3$ days; b) pyridine, $\mathrm{NH}_{2} \mathrm{OR} \cdot \mathrm{HCl}(\mathrm{R}=\mathrm{Me}$, Et, Allyl, or $t \mathrm{But}), 70{ }^{\circ} \mathrm{C}, 24 \mathrm{~h}$; work-up with $\mathrm{KOH}$ in anhydrous $\mathrm{MeOH}$.

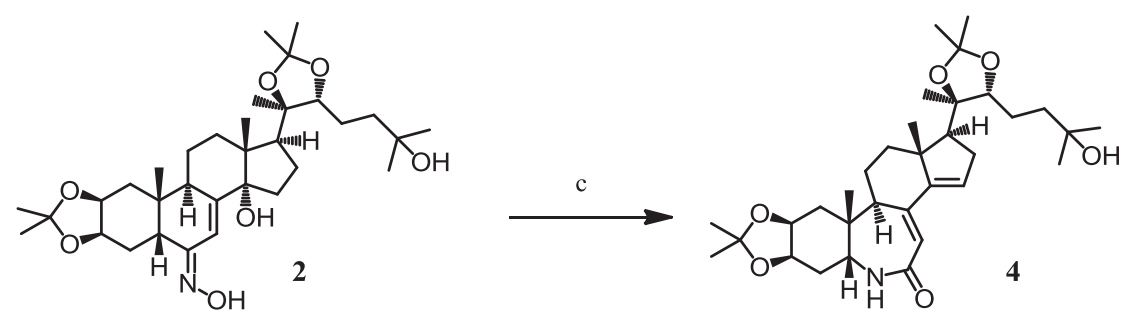

Scheme 2. Beckmann rearrangement of ecdysteroid (6E)-oxime 2 into lactam 4.

Reagents and conditions: c) acetone, p-toluenesulfonyl chloride (TsCl, 2 equiv of oxime 2 ), $\mathrm{Na}_{2} \mathrm{CO}_{3}$ (1 equiv of oxime 2 ), RT, 6 h.

Table 1. The characteristic ${ }^{1} \mathrm{H}$ data of compounds with a $\Delta^{14,15} \mathrm{C}=\mathrm{CH}$ ethylene moiety $\mathbf{2 , 4}$ and $\mathbf{1 1}-\mathbf{1 5}$ are summarized in Table 2, whereas that of the HO-C(14) derivatives $\mathbf{5 - 1 0}$ are shown in Table 3.

It is well known that oximation of ketones is accompanied with characteristic changes of several ${ }^{13} \mathrm{C}$ and ${ }^{1} \mathrm{H}$ chemical shifts. Successful conversion of a $\mathrm{C}=\mathrm{O}$ group to $\mathrm{C}=\mathrm{N}-\mathrm{OH}$ results of ca. $50 \mathrm{ppm}$ diamagnetic shift of the corresponding carbon atom, whereas the chemical shift of $\alpha-\mathrm{CH}$ carbon atom in the syn position with respect to the oxime hydroxyl group exhibits $\sim 14 \mathrm{ppm}$, in the anti position $\sim 9 \mathrm{ppm}$ diamagnetic shift. The significant ( $\Delta \delta$ syn-anti) parameters on $\mathrm{C}-5$ and $=\mathrm{C}-7$ signals successfully can be utilized for the assignment of $(Z / E)$ isomers. Galyautdinov et al. reported some NMR data on 20-hydroxyecdysone oxime [22], including compound 3 ( $Z$ isomer), but they failed on isolating the isomeric compound $\mathbf{2}$ with $Z$ configuration. In addition they have taken the NMR measurements in solvents with rather different anisotropic nature (e.g. pyridine- $d_{5}$, methanol- $d_{4}$ ) and so in some cases the solvation effect was comparable with the $\Delta \delta$ syn-anti parameters. To avoid this ambiguity, we have performed our NMR experiments exclusively in methanol- $d_{4}$.

On the basis of our data, all of the oxime derivatives in Table 1 with $\delta \mathrm{C}-5 \sim 38.6$ and $\delta \mathrm{C}-7 \sim 117.5 \mathrm{ppm}$ values, respectively, are $Z$ isomers, while $\delta \mathrm{C}-5 \sim 43.8$ and $\delta \mathrm{C}-7 \sim 111.0 \mathrm{ppm}$ values assign the $E$ isomers. It is worth noting that the less different $\delta \mathrm{C}-4(\sim 30 / 27 \mathrm{ppm})$ and $\delta$ C- $6(\sim 157 / 161 \mathrm{ppm})$ values also reflect on the $E$ or $Z$ isomers, respectively.

In case of compounds $\mathbf{2}$ and $\mathbf{4}$, and the 6-oxime-ether derivatives 11-15 the DEPTQ and HSQC measurements revealed only seven methylene groups, one less than in the parent compound $\mathbf{1}$, and simultaneously distinctive chemical shift changes appeared at $\delta \mathrm{C}-14: 85.4 \rightarrow \mathrm{C}=\sim 142 \mathrm{ppm}$ and $\delta \mathrm{H}_{2} \underline{\mathrm{C}}-15: 31.8 \rightarrow \mathrm{HC}=\sim 124 \mathrm{ppm}$, respectively, indicating the emergence of an $\Delta^{14,15} \mathrm{C}=\mathrm{CH}$ ethylene moiety. All this means that in these compounds (2, 11-15), simultaneously with the oximation, dehydration by the elimination of the 14-OH group also took place. The presence of the 14-OH substituent in compounds 5-10 appears straightforward, considering of the chemical shift of $\mathrm{C}-14(\delta \mathrm{C}-14-85 \mathrm{ppm})$ confirmed by the HMBC cross-peak $\mathrm{H}_{3}-18 / \mathrm{C}-14$. Success of the Beckmann rearrangement of ecdysteroid (6E)-oxime 2 into lactam 4 could be expected from the $\mathrm{E}$ configuration of the parent oxime. Indeed, the significant (13.1 ppm) paramagnetic shift on $\delta \mathrm{C}-5$ proves that in $\mathbf{4}$ the nitrogen atom coupled to $\mathrm{C}-5$, the appearance of the signal at $170.6 \mathrm{ppm}$ supports the formation of the lactam ring.

Thanks to the comprehensive one- and two-dimensional NMR techniques utilized in the structure elucidation process, a complete ${ }^{1} \mathrm{H}$ signal assignment could be achieved for all compounds. The 
Table 1

${ }^{13} \mathrm{C}$ chemical shifts of compounds $\mathbf{2 , 4 - 1 5}$ as compared to that of their parental compound $\mathbf{1}$ (20-hydroxyecdysone 2,$3 ; 20,22-$ diacetonide) [21]; in methanol- $d_{4}$.

\begin{tabular}{|c|c|c|c|c|c|c|c|c|c|c|c|c|c|c|}
\hline No. & 1 & 2 & $4^{\mathrm{a}}$ & 5 & 6 & 7 & 8 & 9 & 10 & 11 & 12 & 13 & 14 & 15 \\
\hline 1 & 39.0 & 39.5 & 43.2 & 39.7 & 39.7 & 39.4 & 39.7 & 39.4 & 39.8 & 39.1 & 39.1 & 39.1 & 39.3 & 39.5 \\
\hline 2 & 73.7 & 73.4 & 73.2 & 73.6 & 73.6 & 73.6 & 73.6 & 73.6 & 73.7 & 73.4 & 73.5 & 73.5 & 73.6 & 73.6 \\
\hline 3 & 73.3 & 74.0 & 75.5 & 74.0 & 74.0 & 73.9 & 74.0 & 73.8 & 74.2 & 73.7 & 73.8 & 73.8 & 74.0 & 74.1 \\
\hline 4 & 27.9 & 30.3 & 30.9 & 30.0 & 30.0 & 27.0 & 29.9 & 27.0 & 30.0 & 27.3 & 27.2 & 27.2 & 27.3 & 30.4 \\
\hline 5 & 52.7 & 43.5 & 56.6 & 43.8 & 43.8 & 38.6 & 43.8 & 38.7 & 44.0 & 38.4 & 38.5 & 38.6 & 38.2 & 43.7 \\
\hline 6 & 205.8 & 157.0 & 170.6 & 157.2 & 156.9 & 160.3 & 157.4 & 160.7 & 155.7 & 160.8 & 160.6 & 161.0 & 159.4 & 155.8 \\
\hline 7 & 122.0 & 110.0 & 119.9 & 110.7 & 110.9 & 117.5 & 110.8 & 117.3 & 111.3 & 117.0 & 117.2 & 117.0 & 118.3 & 110.8 \\
\hline 8 & 167.1 & 151.5 & 151.6 & 154.1 & 153.8 & 150.7 & 154.1 & 151.0 & 152.3 & 151.0 & 151.1 & 151.1 & 151.3 & 151.6 \\
\hline 9 & 35.9 & 40.2 & 45.9 & 35.5 & 35.5 & 34.4 & 35.5 & 34.4 & 35.7 & 39.1 & 39.2 & 39.2 & 39.2 & 40.2 \\
\hline 10 & 38.9 & 38.0 & 40.7 & 37.8 & 37.7 & 37.0 & 37.7 & 37.0 & 37.6 & 37.1 & 37.1 & 37.1 & 37.0 & 37.9 \\
\hline 11 & 21.8 & 21.9 & 25.4 & 21.5 & 21.5 & 21.5 & 21.5 & 21.5 & 21.5 & 21.8 & 21.8 & 21.9 & 21.9 & 21.9 \\
\hline 12 & 32.5 & 41.3 & 42.4 & 32.6 & 32.6 & 32.5 & 32.6 & 32.5 & 32.6 & 41.1 & 41.1 & 41.1 & 41.2 & 41.3 \\
\hline 13 & 48.7 & 49.0 & 50.2 & 49.0 & 48.6 & 48.3 & 48.6 & 48.3 & 48.6 & 48.6 & 48.6 & 48.7 & 48.6 & 48.7 \\
\hline 14 & 85.4 & 144.3 & 154.4 & 85.9 & 85.9 & 85.7 & 85.9 & 85.7 & 86.0 & 142.4 & 142.1 & 142.4 & 140.6 & 143.8 \\
\hline 15 & 31.8 & 125.3 & 125.6 & 32.0 & 32.0 & 32.1 & 32.0 & 32.1 & 32.0 & 124.4 & 124.3 & 124.4 & 123.6 & 125.0 \\
\hline 16 & 22.6 & 32.4 & 32.6 & 22.6 & 22.6 & 22.7 & 22.6 & 22.6 & 22.6 & 32.3 & 32.3 & 32.4 & 32.3 & 32.4 \\
\hline 17 & 50.6 & 59.0 & 59.3 & 50.6 & 50.6 & 50.7 & 50.6 & 50.7 & 50.6 & 58.9 & 58.9 & 59.0 & 59.0 & 59.1 \\
\hline 18 & 17.8 & 19.7 & 19.6 & 18.0 & 18.0 & 18.0 & 18.0 & 18.0 & 18.1 & 19.6 & 19.6 & 19.6 & 19.6 & 19.7 \\
\hline 19 & 24.2 & 23.9 & 18.1 & 24.3 & 24.3 & 24.3 & 24.3 & 24.3 & 24.3 & 24.1 & 24.0 & 24.1 & 24.1 & 24.9 \\
\hline 20 & 86.0 & 84.9 & 84.7 & 86.0 & 86.0 & 86.1 & 86.0 & 86.1 & 86.0 & 84.9 & 84.9 & 85.0 & 85.0 & 84.9 \\
\hline 21 & 22.8 & 22.0 & 21.9 & 22.7 & 22.7 & 22.7 & 22.7 & 22.7 & 22.7 & 22.0 & 22.0 & 22.0 & 22.0 & 22.0 \\
\hline 22 & 83.5 & 83.1 & 83.1 & 83.4 & 83.4 & 83.4 & 83.4 & 83.4 & 83.4 & 83.2 & 83.2 & 83.2 & 83.2 & 83.2 \\
\hline 23 & 24.9 & 24.8 & 24.8 & 24.8 & 24.8 & 24.8 & 24.8 & 24.8 & 24.8 & 24.8 & 24.8 & 24.9 & 24.9 & 24.9 \\
\hline 24 & 42.4 & 42.1 & 42.1 & 42.3 & 42.3 & 42.4 & 42.3 & 42.4 & 42.3 & 42.1 & 42.1 & 42.1 & 42.1 & 42.7 \\
\hline 25 & 71.3 & 71.2 & 71.2 & 71.2 & 71.2 & 71.2 & 71.2 & 71.2 & 71.2 & 71.1 & 71.2 & 71.2 & 71.2 & 71.2 \\
\hline 26 & 29.1 & 29.0 & 29.1 & 29.1 & 29.1 & 29.1 & 29.1 & 29.1 & 29.1 & 29.1 & 29.0 & 29.0 & 29.0 & 29.0 \\
\hline 27 & 29.0 & 29.7 & 29.6 & 29.6 & 29.6 & 29.6 & 29.6 & 29.5 & 29.6 & 29.7 & 29.7 & 29.7 & 29.7 & 29.7 \\
\hline 28 & 109.6 & & 109.5 & 109.4 & 109.3 & 109.3 & 109.3 & 109.3 & 109.3 & 109.3 & 109.3 & 109.3 & 109.2 & 109.4 \\
\hline $28 \mathrm{Me} \alpha$ & 26.8 & & 26.6 & 26.8 & 26.8 & 26.8 & 26.8 & 26.8 & 26.9 & 26.8 & 26.7 & 26.7 & 26.7 & 26.8 \\
\hline $28 \mathrm{Me} \beta$ & 29.0 & & 28.9 & 29.0 & 29.0 & 29.0 & 29.0 & 29.0 & 29.0 & 29.1 & 29.0 & 29.0 & 29.0 & 29.0 \\
\hline 29 & 108.2 & & 108.0 & 108.1 & 108.0 & 108.1 & 108.0 & 108.1 & 108.0 & 108.0 & 108.0 & 108.1 & 108.0 & 108.1 \\
\hline $29 \mathrm{Me} \alpha$ & 29.5 & & 29.3 & 29.5 & 29.5 & 29.5 & 29.5 & 29.4 & 29.5 & 29.4 & 29.4 & 29.4 & 29.4 & 29.4 \\
\hline $29 \mathrm{Me} \beta$ & 27.3 & & 27.3 & 27.3 & 27.3 & 27.3 & 27.4 & 27.3 & 27.3 & 27.3 & 27.3 & 27.2 & 28.0 & 27.3 \\
\hline $1^{\prime}$ & & & & 61.8 & 70.1 & 70.4 & 75.5 & 75.7 & 78.9 & 62.2 & 70.5 & 75.8 & 79.3 & \\
\hline $2^{\prime}$ & & & & & 15.0 & 15.2 & 135.9 & 136.0 & 28.0 & & 15.2 & 135.9 & 28.0 & \\
\hline $3^{\prime}$ & & & & & & & 117.6 & 117.5 & & & & 117.6 & & \\
\hline
\end{tabular}

a To facilitate the comparison of NMR data of the Beckman product $\mathbf{4}$ and the parental oxime ethers we applied the steroid atomic numbering also for compound $\mathbf{4}$.

characteristic ${ }^{1} \mathrm{H}$ NMR data of the 14,15-anhydro derivatives 2, 4 and 11-15 are summarized in Table 2, whereas that of the other compounds $\mathbf{5 - 1 0}$ in Table 3. The main difference between the two sets of data is that in Table 2, besides $\mathrm{H}-7$, a second olefinic signal appears for $\mathrm{H}-15$ ( $\sim 55.80 \mathrm{dd}$ ) instead of the $\mathrm{H}_{2}-16$ hydrogen signals.

The retained cis junction of the $\mathrm{A} / \mathrm{B}$ rings in each compound was obvious by considering the strong $\mathrm{H}_{3}-19 / \mathrm{H} \beta-5$ ROESY response, whereas the assignment of the $\alpha / \beta$ position of the diastereotopic methylene hydrogens of the skeleton were revealed by the onedimensional selective ROESY measurements irradiating e.g. the $\mathrm{H}_{3}-18, \mathrm{H}_{3}-19$ and $\mathrm{H}-5$ atoms in combination with the observed proton-proton coupling pattern.

Considering the data of Tables 2 and 3 it is clear that the values of $\delta \mathrm{H}-5$ and $\delta \mathrm{H}-7$ chemical shifts allow the easy and unequivocal differentiation between the $E$ and $Z$ isomers. In case of the 14,15anhydro derivatives 2 and 11-15, the $\mathrm{H}-5$ signals resonate around $2.25 \mathrm{ppm}$ in the $E$ and at $3.15 \mathrm{ppm}$ in the $Z$ isomers, and the $\delta \mathrm{H}-7$ chemical shifts appear at $6.76 \mathrm{ppm}$ in the $E$ and at $6.16 \mathrm{ppm}$ in $Z$ isomers. Similar trend was observed for the compounds in Table 3 , the chemical shift of $\mathrm{H}-5$ in the anti position with respect to the oxime hydroxyl group exhibits $\sim 2.23 \mathrm{ppm}$, while in the $Z$ isomer it is $\sim 3.18 \mathrm{ppm}$. The corresponding values for $\mathrm{H}-7$ are 6.45 and $5.88 \mathrm{ppm}$, respectively.

To facilitate the comparison between the NMR data of $Z$ and $E$ isomeric pairs, the stereo-structures with atomic numbering (in red) of compounds 7 (upper) and $\mathbf{6}$ (lower) are shown in Fig. 2. Blue numbers refer to ${ }^{1} \mathrm{H}$ chemical shifts; black numbers give the $\delta{ }^{13} \mathrm{C}$ values.

\subsection{Biology}

Antiproliferative activity of compounds 4-15 was tested on a panel of gynecological cancer cell lines, including cervical (HeLa, $\mathrm{SiHa}$ ) and breast cancer cell lines (MDA-MB-231, MCF7); the results are presented in Table 4

Although most of the ecdysteroid analogs displayed moderate activities against the tested cell lines, the $t$-butyl substituted compound 10 was stronger than the positive control cisplatin on the HeLa and MDA-MB-231 cell lines. In our previous study, the antiproliferative $\mathrm{IC}_{50}$ values of compound 1 were 106.1 and $75.1 \mu \mathrm{M}$ on the MDA-MB-231 and MCF7 cell lines, respectively [21], showing that the inclusion of certain oxime ether functions can increase this activity by nearly an order of magnitude. While the orientation of the oxime ether had no obvious effect on the activity, a larger alkyl group led to a stronger antiproliferative action. It appears to be clear that the retained $14-\mathrm{OH}$ function is favorable over the $\Delta^{14,15}$ moiety in this regard on the MCF-7 cell line (compounds 7 vs. 12, 9 vs. 13, and 10 vs. 15), while such a conclusion cannot be drawn on the other cell lines.

Compounds 2-15 were also tested for their cytotoxic activity on a murine lymphoma cell line pair, including L5178 and its multidrug resistant counterpart transfected to express the human

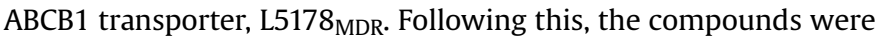
tested for their potential to inhibit the ABCB1 efflux transporter through measuring the intracellular accumulation of rhodamine 123 by flow cytometry. Degree of inhibition (\%) values were calculated by means of the rhodamine 123 accumulation of the ABCB1 transfected L5178 $8_{M D R}$ cells (i.e. $0 \%$ inhibition) and that of the 
Table 2

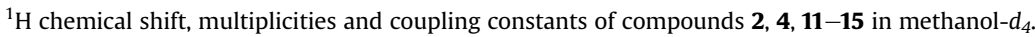

\begin{tabular}{|c|c|c|c|c|c|c|c|c|c|c|c|}
\hline No. & & 2 & $J(\mathrm{~Hz})$ & $4^{a}$ & $J(\mathrm{~Hz})$ & 11 & $J(\mathrm{~Hz})^{\mathrm{b}}$ & 12 & 13 & 14 & 15 \\
\hline \multirow[t]{2}{*}{1} & $\alpha$ & 1.98 & dd; $14.0,6.5$ & 2.19 & dd; $14.0,6.8$ & 1.95 & dd; $13.9,6.3$ & 1.94 & 1.95 & 1.92 & 1.98 \\
\hline & $\beta$ & 1.25 & & 1.30 & & 1.26 & & 1.28 & 1.28 & 1.29 & 1.25 \\
\hline 2 & & 4.19 & ddd; $11.0,6.5,4.5$ & 4.25 & ddd; $12.0,6.8,5.0$ & 4.18 & ddd; $10.8,6.3,4.5$ & 4.19 & 4.19 & 4.19 & 4.19 \\
\hline 3 & & 4.26 & $\mathrm{td} ; 4.5,1.7$ & 4.39 & $\mathrm{dt} ; 5.0,3.0$ & 4.24 & $\mathrm{td} ; 4.5,1.2$ & 4.25 & 4.25 & 4.24 & 4.27 \\
\hline \multirow[t]{2}{*}{4} & $\alpha$ & 1.77 & & 1.29 & & 1.60 & & 1.60 & 1.61 & 1.57 & 1.77 \\
\hline & $\beta$ & 1.97 & & 2.06 & & 2.10 & & 2.11 & 2.14 & 2.11 & 1.95 \\
\hline 5 & & 2.25 & dd; $12.1,4.2$ & 3.30 & dd; $10.2,6.5$ & 3.14 & dd; $12.8,4.6$ & 3.15 & 3.19 & 3.15 & 2.26 \\
\hline 7 & & 6.81 & $\mathrm{~d} ; 2.7$ & 5.94 & $\mathrm{~d} ; 2.6$ & 6.14 & d; 2.6 & 6.16 & 6.16 & 6.20 & 6.70 \\
\hline 9 & & 2.27 & & 2.37 & ddd; $11.5,3.6,2.6$ & 2.31 & & 2.31 & 2.31 & 2.29 & 2.24 \\
\hline \multirow[t]{2}{*}{11} & $\alpha$ & 1.65 & & 1.88 & & 1.63 & & 1.63 & 1.62 & 1.61 & 1.64 \\
\hline & $\beta$ & 1.72 & & 1.74 & & 1.68 & & 1.68 & 1.67 & 1.67 & 1.71 \\
\hline \multirow[t]{2}{*}{12} & $\alpha$ & 1.53 & & 1.60 & & 1.50 & & 1.50 & 1.50 & 1.50 & 1.52 \\
\hline & $\beta$ & 2.23 & & 2.21 & & 2.22 & $\mathrm{dt} ; 12.7,3.0$ & 2.22 & 2.22 & 2.22 & 2.22 \\
\hline 15 & & 5.86 & dd; $3.5,2.0$ & 5.74 & $\mathrm{dd} ; 3.5,1.9$ & 5.81 & dd; 3.3, 2.1 & 5.81 & 5.81 & 5.79 & 5.82 \\
\hline \multirow[t]{2}{*}{16} & $\alpha$ & 2.33 & & 2.33 & & 2.32 & & 2.32 & 2.31 & 2.31 & 2.32 \\
\hline & $\beta$ & 2.60 & & 2.58 & & 2.58 & & 2.58 & 2.58 & 2.58 & 2.59 \\
\hline 17 & & 2.04 & dd; 10.7, 7.7 & 2.11 & dd; $10.7,7.8$ & 2.02 & dd; $10.8,7.7$ & 2.02 & 2.02 & 2.01 & 2.03 \\
\hline 18 & & 1.06 & & 1.06 & & 1.05 & & 1.05 & 1.05 & 1.05 & 1.05 \\
\hline 19 & & 0.83 & & 0.96 & & 0.84 & & 0.84 & 0.85 & 0.84 & 0.81 \\
\hline 21 & & 1.22 & & 1.21 & & 1.22 & & 1.22 & 1.22 & 1.22 & 1.22 \\
\hline 22 & & 3.76 & & 3.75 & & 3.76 & & 3.76 & 3.76 & 3.77 & 3.76 \\
\hline \multirow[t]{2}{*}{23} & $\mathrm{a}$ & 1.53 & & 1.53 & & 1.53 & & 1.53 & 1.53 & 1.53 & 1.54 \\
\hline & $\mathrm{b}$ & 1.53 & & 1.53 & & 1.53 & & 1.53 & 1.53 & 1.53 & 1.54 \\
\hline \multirow[t]{2}{*}{24} & $\mathrm{a}$ & 1.48 & & 1.48 & & 1.48 & & 1.48 & 1.48 & 1.48 & 1.48 \\
\hline & $\mathrm{b}$ & 1.72 & & 1.72 & & 1.72 & & 1.72 & 1.72 & 1.72 & 1.72 \\
\hline 26 & & 1.20 & & 1.20 & & 1.19 & & 1.19 & 1.19 & 1.19 & 1.19 \\
\hline 27 & & 1.21 & & 1.21 & & 1.21 & & 1.20 & 1.20 & 1.21 & 1.21 \\
\hline $28 \mathrm{Me} \alpha$ & & 1.30 & & 1.30 & & 1.31 & & 1.31 & 1.31 & 1.32 & 1.32 \\
\hline $28 \mathrm{Me} \beta$ & & 1.47 & & 1.46 & & 1.49 & & 1.49 & 1.49 & 1.50 & 1.49 \\
\hline $29 \mathrm{Me} \alpha$ & & 1.40 & & 1.40 & & 1.40 & & 1.40 & 1.40 & 1.40 & 1.40 \\
\hline $29 \mathrm{Me} \beta$ & & 1.30 & & 1.30 & & 1.30 & & 1.30 & 1.30 & 1.30 & 1.31 \\
\hline $1^{\prime}$ & & & & & & 3.86 & & 4.11 & 4.56 & - & - \\
\hline $2^{\prime}$ & & & & & & & & 1.27 & 6.00 & 1.29 & 1.29 \\
\hline \multirow[t]{2}{*}{$3^{\prime}$} & $Z$ & & & & & & & & 5.19 & & \\
\hline & $E$ & & & & & & & & 5.29 & & \\
\hline
\end{tabular}

\footnotetext{
a To facilitate the comparison of NMR data of the Beckman product $\mathbf{4}$ and the parental oximethers, we applied the steroid atomic numbering also for $\mathbf{4}$.
}

b Because the stereostucture of the steroid frame is nearly identical within compounds $\mathbf{1 1 - 1 5}$, we described the $J$ coupling contents only for $\mathbf{1 1}$.

L5178 cells (i.e. 100\% inhibition); results are presented in Table 5.

While the compounds also exerted weak to moderate cytotoxic activities on the mouse lymphoma cell line pair, all of them were more potent than their parental compound 1. No cross resistance was observed to any of them on the ABCB1 over-expressing MDR cells. The oximes $\mathbf{2}$ and $\mathbf{3}$ showed the strongest activity on either cell lines with $\mathrm{IC}_{50}$ values ca. $4-5$ times below that of compound $\mathbf{1}$, and the $E$-oxime (2) was more cytotoxic than the $Z$-oxime (3). The oxime ethers typically exerted weaker cytotoxic activities than the non-substituted oximes, with the exception of compound $\mathbf{1 0}$ where a bulky $t$-butyl substituent and a retained 14-OH group were present. When comparing corresponding analogs with a retained 14$\mathrm{OH}$ group or a $\Delta^{14,15}$ moiety, there appeared to be a clear tendency for the former structural element to be associated with a stronger cytotoxic activity on the mouse lymphoma cells, similarly to the case of MCF-7 cells (see above).

Evaluation of the results obtained from the rhodamine accumulation assay reveals that the lactam derivative (4) is the only one among the compounds that was completely inactive in this regard at as much as $20 \mu \mathrm{M}$ concentration. For the other compounds, several structure-activity relationships could be observed. The oxime formation markedly increased the ABCB1 inhibitory activity, and this was particularly true for oxime ethers. The orientation of the oxime group had little if any influence on the ABCB1 inhibition (compound 2 vs. 3, 6 vs. 7, 8 vs. 9, and 14 vs. 15), while the 14-OH elimination, forming a $\Delta^{14,15}$ double bond in the ecdysteroid Dring, clearly increased this activity (compound 7 vs. 12, 9 vs. 13, and 10 vs. 15). When comparing the activity of oximes and oxime ethers between analogs containing the same type of D-ring and orientation of oxime but different substituents on the latter, the following order of bioactivity could be concluded: $\mathrm{H}<\mathrm{Me}<$ Et $<$ Allyl $\leq t$-But.

The compounds were also tested for their ability to sensitize the susceptible/resistant mouse lymphoma cell line pair towards the cytotoxic activity of doxorubicin. Since each compound showed a measurable cytotoxic activity on both cell lines when applied alone, combination indices could be determined through the checkerboard microplate method similarly to our previous related studies $[17,19]$. Table 6 shows the strongest activity observed for each compound on the L5178 and L5178 ${ }_{\mathrm{MDR}}$ cell lines; further details and results at other compound:doxorubicin ratios are available in supporting information Table S1.

All tested derivatives showed strong synergism $\left(0.1<\mathrm{Cl}_{\mathrm{avg}}<0.3\right)$ [25] with doxorubicin on the P-gp expressing L5178 $\mathrm{MDR}$ cells, similarly to their parental compound (1). As it was previously reported by us, chemo-sensitizing activity of ecdysteroids has little if any correlation to their (most typically weak) inhibitory effect on the efflux function of P-gp [20]. This was clearly confirmed in the present study as well: even though for example compounds 11-15 are much stronger P-gp inhibitors than their parental compound $\mathbf{1}$, no difference can be observed in the strength of synergism with the P-gp substrate doxorubicin on the MDR cell line. Most interestingly, among all derivatives obtained, the ecdysteroid lactam 4 was found to express the strongest chemosensitization on the MDR cells, while being the only one to show no interference with P-gp function. Accordingly, this compound has a further advantage over the diacetonide of $20 \mathrm{E}$, namely that it would likely be free from the potential adverse effects and unwanted drug-drug interactions 
Table 3

${ }^{1} \mathrm{H}$ chemical shifts, multiplicities and coupling constants of compounds 5-10 in methanol- $d_{4}$

\begin{tabular}{|c|c|c|c|c|c|c|c|c|}
\hline No. & & 5 & $J(\mathrm{~Hz})^{\mathrm{a}}$ & 6 & 7 & 8 & 9 & 10 \\
\hline \multirow[t]{2}{*}{1} & $\alpha$ & 1.98 & & 1.98 & 1.94 & 1.98 & 1.95 & 1.98 \\
\hline & $\beta$ & 1.22 & & 1.23 & 1.24 & 1.23 & 1.24 & 1.23 \\
\hline 2 & & 4.21 & ddd; $10.5,6.7,5.1$ & 4.21 & 4.21 & 4.22 & 4.21 & 4.22 \\
\hline 3 & & 4.28 & & 4.28 & 4.26 & 4.28 & 4.27 & 4.28 \\
\hline \multirow[t]{2}{*}{4} & $\alpha$ & 1.93 & & 1.93 & 1.73 & 1.93 & 1.74 & 1.92 \\
\hline & $\beta$ & 1.93 & & 1.93 & 2.06 & 1.93 & 2.08 & 1.92 \\
\hline 5 & & 2.22 & $\mathrm{dd} ; 12.2,5.5$ & 2.23 & 3.16 & 2.24 & 3.19 & 2.26 \\
\hline 7 & & 6.44 & $\mathrm{~d} ; 2.7$ & 6.47 & 5.88 & 6.49 & 5.88 & 6.47 \\
\hline 9 & & 2.72 & ddd; $11.8,6.9,2.7$ & 2.71 & 2.72 & 2.72 & 2.73 & 2.70 \\
\hline \multirow[t]{2}{*}{11} & $\alpha$ & 1.65 & & 1.65 & 1.65 & 1.64 & 1.63 & 1.64 \\
\hline & $\beta$ & 1.59 & & 1.58 & 1.58 & 1.59 & 1.58 & 1.59 \\
\hline \multirow[t]{2}{*}{12} & $\alpha$ & 2.03 & $\mathrm{td} ; 12.0,5.5$ & 2.04 & 2.04 & 2.04 & 2.04 & 2.03 \\
\hline & $\beta$ & 1.80 & $\mathrm{dm} ; 12.0$ & 1.81 & 1.80 & 1.81 & 1.80 & 1.80 \\
\hline \multirow[t]{2}{*}{15} & $\alpha$ & 1.61 & & 1.62 & 1.63 & 1.62 & 1.63 & 1.62 \\
\hline & $\beta$ & 1.96 & & 1.97 & 1.94 & 1.97 & 1.94 & 1.96 \\
\hline \multirow[t]{2}{*}{16} & $\alpha$ & 1.85 & & 1.85 & 1.85 & 1.86 & 1.85 & 1.85 \\
\hline & $\beta$ & 2.00 & & 2.00 & 2.02 & 2.01 & 2.02 & 2.02 \\
\hline 17 & & 2.28 & dd; 9.1, 7.8 & 2.28 & 2.27 & 2.29 & 2.27 & 2.28 \\
\hline 18 & & 0.80 & & 0.81 & 0.81 & 0.81 & 0.81 & 0.81 \\
\hline 19 & & 0.83 & & 0.83 & 0.84 & 0.83 & 0.85 & 0.82 \\
\hline 21 & & 1.17 & & 1.17 & 1.17 & 1.17 & 1.17 & 1.17 \\
\hline 22 & & 3.68 & & 3.68 & 3.68 & 3.68 & 3.68 & 3.68 \\
\hline \multirow[t]{2}{*}{23} & $\mathrm{a}$ & 1.52 & & 1.52 & 1.52 & 1.52 & 1.52 & 1.52 \\
\hline & $\mathrm{b}$ & 1.52 & & 1.52 & 1.52 & 1.52 & 1.52 & 1.52 \\
\hline \multirow[t]{2}{*}{24} & $\mathrm{a}$ & 1.48 & & 1.48 & 1.49 & 1.48 & 1.49 & 1.49 \\
\hline & $\mathrm{b}$ & 1.73 & & 1.73 & 1.73 & 1.73 & 1.73 & 1.74 \\
\hline 26 & & 1.19 & & 1.19 & 1.19 & 1.19 & 1.19 & 1.19 \\
\hline 27 & & 1.20 & & 1.20 & 1.20 & 1.20 & 1.20 & 1.20 \\
\hline $28 \mathrm{Me} \alpha$ & & 1.31 & & 1.31 & 1.32 & 1.31 & 1.32 & 1.32 \\
\hline $28 \mathrm{Me} \beta$ & & 1.47 & & 1.47 & 1.50 & 1.47 & 1.49 & 1.49 \\
\hline $29 \mathrm{Me} \alpha$ & & 1.39 & & 1.39 & 1.39 & 1.39 & 1.39 & 1.39 \\
\hline $29 \mathrm{Me} \beta$ & & 1.32 & & 1.32 & 1.32 & 1.32 & 1.32 & 1.32 \\
\hline $1^{\prime}$ & & 3.82 & & 4.07 & 4.10 & 4.53 & 4.55 & - \\
\hline $2^{\prime}$ & & & & 1.25 & 1.26 & 5.98 & 5.99 & 1.28 \\
\hline \multirow[t]{2}{*}{$3^{\prime}$} & $Z$ & & & & & 5.18 & 5.19 & \\
\hline & $E$ & & & & & 5.26 & 5.28 & \\
\hline
\end{tabular}

${ }^{a}$ Because the stereo-structure of the steroid frame is nearly identical within this set of compounds, the $J$ coupling constants are given only once.

connected to P-gp inhibitors [26,27].

Considering structure-activity relationships, the several highly active compounds obtained in this work led us to follow our previously applied "best ratio" principle [17]. This means that we aimed to compare the compounds' chemo-sensitizing activities at their strongest, regardless of the compound vs. doxorubicin ratio where this activity was observed.

The length or nature of the alkyl function had no apparent effect on the compounds potency in sensitizing the MDR cells to doxorubicin, all compounds showed similarly high activity in this regard. A slight tendency may be observed for the $\Delta^{14,15}$ compounds $(2-4,11-15)$ acting stronger in this regard than their corresponding analogs where the 14-OH group was retained $(\mathbf{5}-\mathbf{1 0})$, but the differences are so small that it is hard to make a sound judgment on the relevance of this phenomenon.

On the other hand, larger differences were observed between the compounds' activities on the non-MDR L5178 cells. On this cell line, the strongest synergism with doxorubicin was observed for the lactam (4) and compound 11, a methyl substituted $\Delta^{14,15}(Z)$ oxime ether. The oxime formation together with the elimination of the 14-OH group (2 and $\mathbf{3}$ ) decreased the strength of synergism with doxorubicin as compared to the case of compound $\mathbf{1}$. In case of the oxime ethers, the 14,15-anhydro derivatives typically exerted stronger sensitizing activity to doxorubicin than their analogs with intact 14-OH groups, except for compounds $\mathbf{1 0}$ vs. 15. Since oxime ethers substituted with bulky $t$-buthyl groups seem to show a tendency for decreased activity as compared to the corresponding analogs with ethyl groups (6 vs 10 and 12 vs. 14), one could hypothesize that the effect of the $t$-butyl group in the oxime ether function may overwrite that of the $\Delta^{14,15}$ moiety in compound $\mathbf{1 5}$.

\section{Conclusions}

The present study reports the preparation and in vitro pharmacological investigation of 14 ecdysteroid diacetonide oximes, oxime ethers and a lactam, with 13 novel derivatives obtained in pure form for the first time. The synthetic procedure was utilized in a way to obtain product mixtures in order to increase chemical diversity, and subsequent use of high-performance separation techniques allowed us to obtain the compounds in high purity. All compounds are reported with a complete NMR signal assignment.

Evaluation of the antiproliferative and cytotoxic activity of the compounds on several cancer cell lines revealed several structureactivity relationships (SAR). A new, $t$-butyl substituted ecdysteroid oxime ether (10) was found to exert stronger antiproliferative effect on HeLa and MDA-MB-231 cells than cisplatin. The $\Delta^{14,15}$ E-oxime derivative (2) exerted a substantially increased cytotoxic and P-gp inhibitory activities in the $\mathrm{L} 5178 / \mathrm{L}^{2} 178_{\mathrm{MDR}}$ cell line pair, as compared to its parental compound.

Clear SAR was observed for the compounds' activity as functional P-gp inhibitors, and many of them were identified as highly potent MDR-selective chemo-sensitizers. In particularly, a novel $\Delta^{14,15} \delta$-lactam ecdysteroid derivative (4) was revealed as a most promising new lead compound with low intrinsic cytotoxicity, and strong ability to sensitize MDR and also non-MDR cancer cells towards doxorubicin without interfering with the efflux function of P-gp. Accordingly, it can be expected that a combined treatment of cancer with this compound as a chemo-sensitizer and a chemotherapeutic agent would 1) be effective on the initial, susceptible state of the tumor, and 2) have a strong chance to prevent the acquisition of P-gp mediated resistance through an increased killing effect on the cell population becoming adapted to the chemotherapy.

\section{Experimental section}

\subsection{Chemistry}

All applied reagents were purchased from Sigma (Sigma-Aldrich Co., USA). Solvents were obtained from Macron Fine Chemicals (Avantor Performance Materials, USA).

${ }^{1} \mathrm{H}(500.1 \mathrm{MHz})$ and ${ }^{13} \mathrm{C}(125.6 \mathrm{MHz})$ NMR spectra were recorded at room temperature on a Bruker Avance-II spectrometer and on Avance-III spectrometer equipped with a cryo probehead. Regarding the compounds, amounts of approximately $1-10 \mathrm{mg}$ were dissolved in $0.1 \mathrm{ml}$ of methanol- $d_{4}$ and transferred to $2.5 \mathrm{~mm}$ Bruker MATCH NMR sample tube. Chemical shifts are given on the $\delta$-scale and are referenced to the solvent $\left(\mathrm{MeOH}-d_{4}: \delta_{\mathrm{C}}=49.1\right.$ and $\left.\delta_{\mathrm{H}}=3.31 \mathrm{ppm}\right)$. Pulse programs of all experiments $\left({ }^{1} \mathrm{H},{ }^{13} \mathrm{C}\right.$, DEPTQ DEPT-135, one-dimensional sel-ROE (mixing time: $300 \mathrm{~ms}$ ), edited gs-HSQC and gs-HMBC) were taken from the Bruker software library. The NMR signals of the product were assigned by comprehensive one- and two-dimensional NMR methods using widely accepted strategies $[28,29,30]$. Most ${ }^{1} \mathrm{H}$ assignments were accomplished using general knowledge of chemical shift dispersion with the aid of the proton-proton coupling pattern $\left({ }^{1} \mathrm{H}\right.$ NMR spectra). Mass spectra were obtained on a Waters Acquity iClass UPLC coupled with Thermo Q Exactive Plus with HESI source (Waters Co., USA).

Reaction progress was monitored by thin layer chromatography (TLC) on Kieselgel $60 \mathrm{~F}_{254}$ silica plates obtained from Merck (Merck, Germany), and examined under UV illumination at $254 \mathrm{~nm}$. 

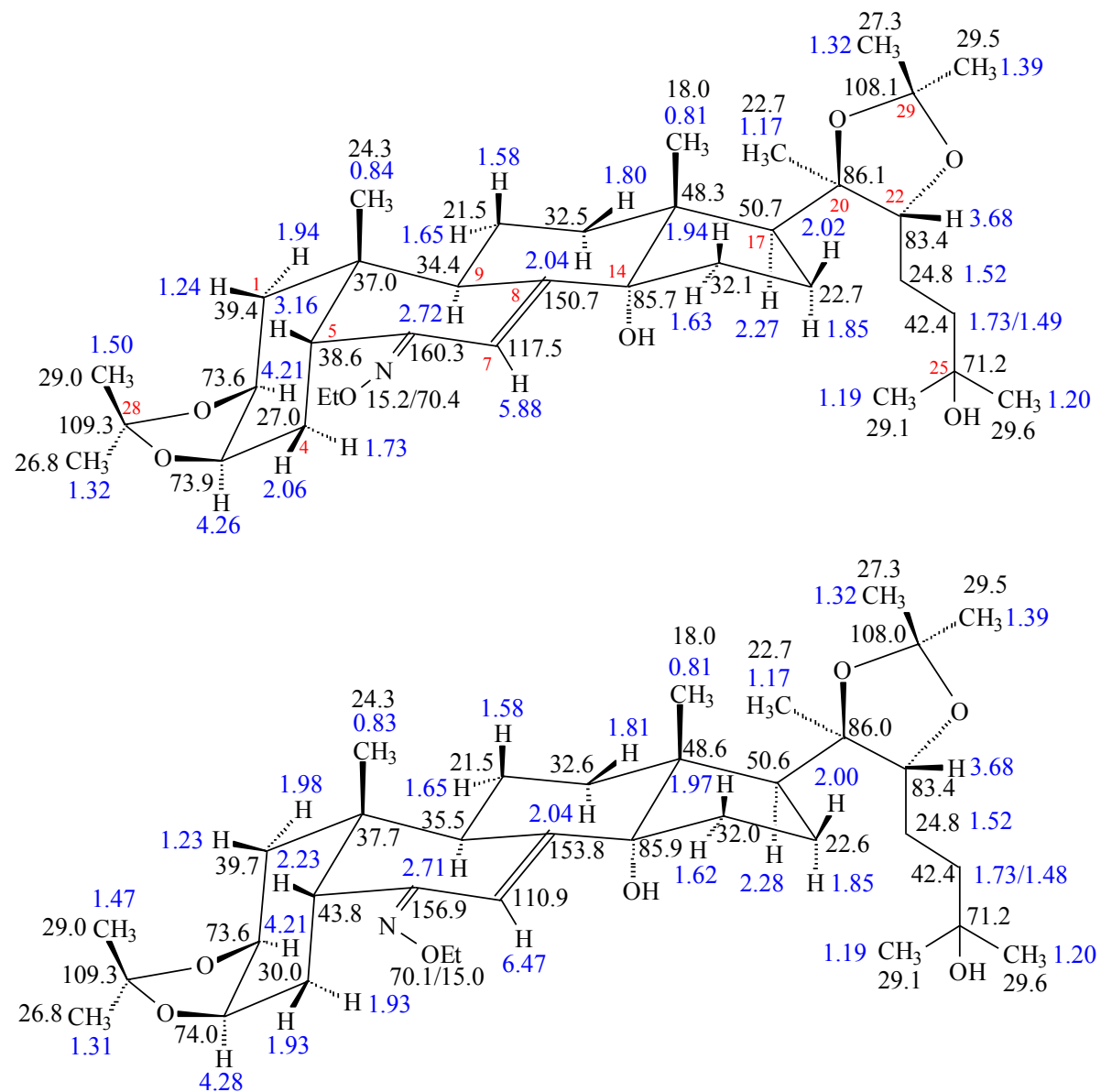

Fig. 2. Characteristic NMR spectra on differentiation and NMR assignments of the isomeric $\mathbf{6}$ and $\mathbf{7}$ ecdysteroid 6-oxime ethers are given in the supporting information.

Table 4

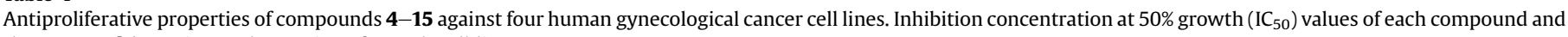
the $95 \%$ confidence intervals are given for each cell line.

\begin{tabular}{|c|c|c|c|c|}
\hline \multirow[t]{2}{*}{ Compound } & \multicolumn{4}{|l|}{$\mathrm{IC}_{50}(\mu \mathrm{M})$} \\
\hline & HeLa & $\mathrm{SiHa}$ & MDA-MB-231 & MCF7 \\
\hline 4 & $>30$ & $>30$ & $>30$ & $>30$ \\
\hline 5 & $>30$ & $>30$ & $>30$ & $>30$ \\
\hline 6 & $>30$ & $>30$ & $>30$ & $22.55[17.24-29.50]$ \\
\hline 7 & $29.12[24.00-32.94]$ & $>30$ & 25.12 [17.74-35.57] & 13.10 [10.89-15.77] \\
\hline 8 & 15.55 [13.69-17.66] & 25.52 [21.95-29.68] & 21.36 [18.86-24.19] & $13.63[11.91-15.60]$ \\
\hline 9 & $17.55[14.77-20.84]$ & $>30$ & $26.90[23.34-31.00]$ & $17.22[15.21-19.50]$ \\
\hline 10 & $8.43[4.66-9.29]$ & 16.13 [13.02-19.99] & $12.36[11.00-13.89]$ & $11.06[9.96-12.29]$ \\
\hline 11 & 15.43 [12.87-18.50] & $>30$ & 25.99 [21.67-29.50] & $18.03[15.86-20.50]$ \\
\hline 12 & $29.96[27.03-33.20]$ & $>30$ & $26.00[23.44-28.85]$ & 19.59 [17.09-22.46] \\
\hline 13 & $>30$ & $>30$ & 29.37 [26.11-33.03] & $24.16[20.36-28.68]$ \\
\hline 14 & $20.71[18.63-23.02]$ & 8.14 [5.62-11.79] & $15.70[13.50-18.25]$ & $17.29[15.33-19.52]$ \\
\hline 15 & $26.06[22.45-30.25]$ & 14.17 [10.60-18.94] & 16.93 [14.71-19.49] & $19.34[16.51-22.66]$ \\
\hline Cisplatin & $14.02[12.65-15.56]$ & $7.87[5.83-10.63]$ & $18.65[16.67-20.85]$ & $6.01[5.33-6.79]$ \\
\hline
\end{tabular}

Compounds were purified by flash chromatography with adequately chosen eluents of $n$-hexane - dichloromethane methanol on $12 \mathrm{~g}$ RediSep NP-silica flash columns (TELEDYNE Isco, USA).

For the RP-HPLC separation of isomeric oxime derivatives a Kinetex XB-C18 $250 \times 21.4 \mathrm{~mm} 5 \mu \mathrm{m}$ preparative (Phenomenex Inc., USA) or an Agilent Eclipse XDB-C8 $250 \times 9.4 \mathrm{~mm} 5 \mu \mathrm{m}$ semipreparative column (Agilent Technologies Inc., USA) was applied with the use of isocratic grade eluents of acetonitrile and water. Purity of obtained compounds was determined by RP-HPLC with the use of a Kinetex XB-C18 $250 \times 4.6 \mathrm{~mm} 5 \mu \mathrm{m}$ analytical column (Phenomenex Inc., USA). For data collection a Jasco HPLC instrument equipped with an MD-2010 Plus PDA detector (Jasco Analytical Instruments, Japan) was applied in a detection range of $210-400 \mathrm{~nm}$.

Ecdysteroid substrate $\mathbf{1}$ was synthesized from 20hydroxyecdysone (20E) obtained from Shaanxi KingsSci Biotechnology Co., Ltd. (Shanghai, People's Republic of China) at 90\% purity and recrystallized (EtOAc:MeOH - 2:1) to a RP-HPLC purity of $97.8 \%$. During the synthetic procedure, 20E (10 g) was dissolved in 
Table 5

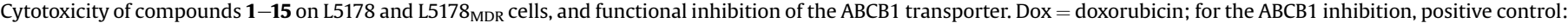
$100 \mathrm{nM}$ of tariquidar (112.4\% inhibition), negative control: $2 \%$ DMSO ( $-0.07 \%$ inhibition).

\begin{tabular}{|c|c|c|c|c|c|c|}
\hline \multirow[t]{2}{*}{ Compound } & \multirow{2}{*}{$\frac{\text { Change in the }}{\text { B-ring of } 1^{\mathrm{a}}}$} & \multirow{2}{*}{$\frac{14-\mathrm{OH} \text { or }}{\Delta^{14,15}}$} & \multicolumn{2}{|c|}{$\mathrm{IC}_{50}(\mu \mathrm{M})[95 \% \text { confidence intervals }]^{\mathrm{b}}$} & \multicolumn{2}{|c|}{ ABCB1 inhibition (\%) } \\
\hline & & & L5178 & L5178 $8_{\mathrm{MDR}}$ & $2 \mu \mathrm{M}$ & $20 \mu \mathrm{M}$ \\
\hline 1 & - & $14-\mathrm{OH}$ & $110.3[77.50-157.1]$ & 97.69 [71.07-134.3] & 2.54 & 20.91 \\
\hline 2 & (E)-oxime & $\Delta^{14,15}$ & $20.91[17.68-24.74]$ & $24.63[19.82-30.63]$ & 10.57 & 82.95 \\
\hline 3 & (Z)-oxime & $\Delta^{14,15}$ & $34.22[28.21-41.51]$ & 28.35 [21.97-36.58] & 7.15 & 81.09 \\
\hline 4 & $\delta$-lactam & $\Delta^{14,15}$ & $63.42[47.51-84.65]$ & 72.35 [64.39-81.29] & 1.16 & 4.27 \\
\hline 5 & $(E) ; \mathrm{R}=\mathrm{Me}$ & $14-\mathrm{OH}$ & $40.92[35.66-46.97]$ & $55.05[41.53-72.98]$ & 2.25 & 25.05 \\
\hline 6 & $(E) ; \mathrm{R}=\mathrm{Et}$ & $14-\mathrm{OH}$ & $35.02[25.35-48.38]$ & $47.00[31.14-70.93]$ & 17.54 & 78.79 \\
\hline 7 & $(Z) ; \mathrm{R}=\mathrm{Et}$ & $14-\mathrm{OH}$ & $37.26[25.65-54.11]$ & $42.16[41.24-43.10]$ & 18.96 & 75.03 \\
\hline 8 & $(E) ; \mathrm{R}=$ Allyl & $14-\mathrm{OH}$ & $31.48[23.71-41.80]$ & 51.91 [42.69-63.13] & 20.98 & 89.39 \\
\hline 9 & $(Z) ; \mathrm{R}=$ Allyl & $14-\mathrm{OH}$ & $36.66[28.32-47.44]$ & $49.29[43.07-56.40]$ & 24.17 & 81.80 \\
\hline 10 & $(E) ; \mathrm{R}=t$-But & $14-\mathrm{OH}$ & $28.06[21.30-36.98]$ & $29.12[25.12-33.76]$ & 38.75 & 112.4 \\
\hline 11 & $(Z) ; \mathrm{R}=\mathrm{Me}$ & $\Delta^{14,15}$ & $45.95[36.97-57.11]$ & $53.14[43.54-64.86]$ & 33.36 & 106.2 \\
\hline 12 & $(Z) ; \mathrm{R}=\mathrm{Et}$ & $\Delta^{14,15}$ & $53.20[38.64-73.26]$ & $58.94[45.86-75.74]$ & 56.41 & 107.7 \\
\hline 13 & $(Z) ; \mathrm{R}=$ Allyl & $\Delta^{14,15}$ & $55.28[46.21-66.13]$ & 52.72 [39.97-65.53] & 61.13 & 102.7 \\
\hline 14 & $(Z) ; \mathrm{R}=t$-But & $\Delta^{14,15}$ & $63.23[58.57-68.26]$ & $51.22[39.13-67.04]$ & 58.99 & 78.76 \\
\hline 15 & $(E) ; \mathrm{R}=t$-But & $\Delta^{14,15}$ & $63.84[45.70-89.19]$ & $65.44[55.66-76.94]$ & 67.46 & 93.95 \\
\hline Dox & - & - & $0.080[0.053-0.12]$ & $4.49[3.43-5.89]$ & - & - \\
\hline
\end{tabular}

${ }^{\mathrm{a}} \mathrm{R}$ groups refer to the alkyl substituents of the oxime ethers as in Scheme 1.

${ }^{b} \mathrm{IC}_{50}$ values were calculated by the CompuSyn software as the median cytotoxic activities (Dm) from the control lanes on the checkerboard plates of the combination studies, $\mathrm{n}=2$.

Table 6

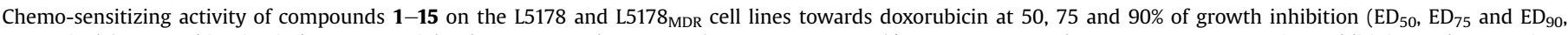

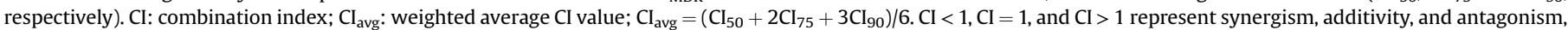
respectively. Dm, $\mathrm{m}$, and $\mathrm{r}$ represent antilog of the $\mathrm{x}$-intercept, slope, and linear correlation coefficient of the median-effect plot, respectively.

\begin{tabular}{|c|c|c|c|c|c|c|c|c|c|}
\hline \multirow[t]{2}{*}{ Compound } & \multirow[t]{2}{*}{ Cell line } & \multirow[t]{2}{*}{ Drug ratio } & \multicolumn{3}{|l|}{$\mathrm{CI}$ at } & \multirow[t]{2}{*}{$\mathrm{Dm}$} & \multirow[t]{2}{*}{$\mathrm{m}$} & \multirow[t]{2}{*}{$r$} & \multirow[t]{2}{*}{$\mathrm{Cl}_{\mathrm{avg}}$} \\
\hline & & & $\mathrm{ED}_{50}$ & $\mathrm{ED}_{75}$ & $\mathrm{ED}_{90}$ & & & & \\
\hline \multirow[t]{2}{*}{1 [21] } & $\mathrm{L} 5178_{\mathrm{MDR}}$ & 20.4: 1 & 0.27 & 0.14 & 0.07 & 11.678 & 3.246 & 0.964 & 0.13 \\
\hline & L5178 & 163: 1 & 0.67 & 0.55 & 0.46 & 11.236 & 2.103 & 0.942 & 0.53 \\
\hline \multirow[t]{2}{*}{2} & $\mathrm{~L} 5178_{\mathrm{MDR}}$ & 15: 1 & 0.26 & 0.16 & 0.12 & 4.454 & 6.638 & 1.000 & 0.16 \\
\hline & L5178 & 150: 1 & 0.80 & 0.79 & 0.78 & 10.748 & 2.572 & 0.997 & 0.78 \\
\hline \multirow[t]{2}{*}{3} & $\mathrm{~L} 5178_{\mathrm{MDR}}$ & 30: 1 & 0.32 & 0.25 & 0.20 & 7.595 & 3.981 & 0.994 & 0.24 \\
\hline & L5178 & 150: 1 & 0.98 & 0.76 & 0.61 & 16.049 & 3.239 & 0.986 & 0.72 \\
\hline \multirow[t]{2}{*}{4} & $\mathrm{~L} 5178_{\mathrm{MDR}}$ & 15: 1 & 0.20 & 0.12 & 0.09 & 6.419 & 4.953 & 0.970 & 0.12 \\
\hline & L5178 & 150: 1 & 0.40 & 0.42 & 0.46 & 10.477 & 2.033 & 0.966 & 0.44 \\
\hline \multirow[t]{2}{*}{5} & $\mathrm{~L} 5178_{\mathrm{MDR}}$ & 15: 1 & 0.17 & 0.16 & 0.16 & 6.605 & 3.721 & 0.978 & 0.16 \\
\hline & L5178 & 150: 1 & 1.06 & 0.79 & 0.62 & 14.306 & 2.947 & 0.971 & 0.75 \\
\hline \multirow[t]{2}{*}{6} & L5178 ${ }_{M D R}$ & 7.5: 1 & 0.18 & 0.14 & 0.12 & 5.001 & 5.858 & 1.000 & 0.14 \\
\hline & L5178 & 37.5: 1 & 0.55 & 0.58 & 0.60 & 8.598 & 2.495 & 0.972 & 0.59 \\
\hline \multirow[t]{2}{*}{7} & $\mathrm{~L} 5178_{\mathrm{MDR}}$ & 3.75: 1 & 0.27 & 0.16 & 0.13 & 3.030 & 3.329 & 0.993 & 0.16 \\
\hline & L5178 & 37.5: 1 & 0.63 & 0.52 & 0.45 & 8.078 & 3.858 & 0.952 & 0.50 \\
\hline \multirow[t]{2}{*}{8} & $\mathrm{~L} 5178_{\mathrm{MDR}}$ & 15: 1 & 0.17 & 0.13 & 0.13 & 4.939 & 3.193 & 0.955 & 0.14 \\
\hline & L5178 & $150: 1$ & 1.03 & 0.81 & 0.69 & 8.970 & 2.178 & 0.991 & 0.79 \\
\hline \multirow[t]{2}{*}{9} & $\mathrm{~L} 5178_{\mathrm{MDR}}$ & $15: 1$ & 0.17 & 0.16 & 0.17 & 7.338 & 3.771 & 0.947 & 0.17 \\
\hline & L5178 & $75: 1$ & 0.70 & 0.83 & 1.03 & 8.202 & 1.722 & 0.956 & 0.91 \\
\hline \multirow[t]{2}{*}{10} & $\mathrm{~L} 5178_{\mathrm{MDR}}$ & $7.5: 1$ & 0.30 & 0.20 & 0.17 & 3.928 & 4.610 & 1.000 & 0.20 \\
\hline & L5178 & 37.5: 1 & 0.58 & 0.63 & 0.70 & 7.606 & 2.502 & 0.966 & 0.66 \\
\hline \multirow[t]{2}{*}{11} & $\mathrm{~L} 5178_{\mathrm{MDR}}$ & $7.5: 1$ & 0.17 & 0.16 & 0.15 & 5.224 & 3.722 & 0.971 & 0.16 \\
\hline & L5178 & 37.5: 1 & 0.77 & 0.47 & 0.31 & 8.165 & 3.044 & 0.982 & 0.44 \\
\hline \multirow[t]{2}{*}{12} & $\mathrm{~L} 5178_{\mathrm{MDR}}$ & $7.5: 1$ & 0.21 & 0.14 & 0.11 & 6.133 & 4.890 & 0.992 & 0.14 \\
\hline & L5178 & $75: 1$ & 0.49 & 0.50 & 0.52 & 7.864 & 2.094 & 0.961 & 0.51 \\
\hline \multirow[t]{2}{*}{13} & $\mathrm{~L} 5178_{\mathrm{MDR}}$ & 3.75: 1 & 0.25 & 0.15 & 0.11 & 5.614 & 5.805 & 1.000 & 0.15 \\
\hline & L5178 & 37.5: 1 & 0.46 & 0.47 & 0.47 & 8.295 & 2.882 & 0.981 & 0.47 \\
\hline \multirow[t]{2}{*}{14} & $\mathrm{~L} 5178_{\mathrm{MDR}}$ & 7.5: 1 & 0.34 & 0.26 & 0.23 & 8.365 & 3.378 & 0.939 & 0.26 \\
\hline & L5178 & 37.5: 1 & 0.53 & 0.59 & 0.66 & 9.652 & 2.400 & 0.961 & 0.62 \\
\hline \multirow[t]{2}{*}{15} & $\mathrm{~L} 5178_{\mathrm{MDR}}$ & 7.5: 1 & 0.27 & 0.24 & 0.23 & 8.739 & 3.813 & 0.960 & 0.24 \\
\hline & L5178 & 37.5: 1 & 1.16 & 0.85 & 0.64 & 7.199 & 3.273 & 0.977 & 0.80 \\
\hline
\end{tabular}

acetone in the concentration of $\mathrm{g} / 100 \mathrm{~cm}^{3}$ and phosphomolybdic acid was added $(10 \mathrm{~g})$ under stirring. After 5 min of stirring at RT the reaction mixture was neutralized with $10 \%$ aqueous $\mathrm{NaHCO}_{3}$. Acetone was evaporated under reduced pressure and the mixture was extracted with EtOAc $(3 \times 50 \mathrm{ml})$ followed by drying with $\mathrm{Na}_{2} \mathrm{SO}_{4}$. After filtration, the solvent was evaporated under reduced pressure and the crude mixture was purified by flash chromatography with isocratic grade eluents of dichloromethane:methanol -
99:1. (Yield: 51\%).

Synthesis of ecdysteroid 6-oximes (2-3). $1 \mathrm{~g}$ of compound 1 $(1,78 \mathrm{mmol})$ was dissolved in pyridine $(10 \mathrm{ml})$ and $1 \mathrm{~g}$ of hydroxylamine hydrochloride $(14.39 \mathrm{mmol})$ was added to the solution under stirring. After 3 days of stirring at $70^{\circ} \mathrm{C}$ the reaction was complete and the solvent was evaporated under reduced pressure. Following water addition $(50 \mathrm{ml})$, the mixture was extracted with EtOAc $(3 \times 50 \mathrm{ml})$ and the combined organic phase was dried with 
$\mathrm{Na}_{2} \mathrm{SO}_{4}$. A filtration was made to remove drying agent and the solvent was evaporated under reduced pressure. Purification of the crude mixture was carried out by preparative RP-HPLC to obtain (E/ Z)-isomeric oximes 2-3, respectively.

Synthesis of ecdysteroid lactam derivative (4). $0.138 \mathrm{~g}$ of oxime $2(0,25 \mathrm{mmol})$ was dissolved in anhydrous acetone $(10 \mathrm{ml})$, then $0.027 \mathrm{~g}$ of $\mathrm{Na}_{2} \mathrm{CO}_{3}(0.25 \mathrm{mmol})$ and $0.096 \mathrm{~g}$ of $p$-toluenesulfonyl chloride $(0,5 \mathrm{mmol})$ was added to the solution under stirring. After $6 \mathrm{~h}$ of stirring at RT, the reaction was stopped and the mixture was cooled to $0^{\circ} \mathrm{C}$. Under stirring, water $(10 \mathrm{ml})$ was added and the mixture was extracted into ethyl acetate $(3 \times 50 \mathrm{ml})$. After evaporation under reduced pressure, the mixture was purified with semi-preparative RP-HPLC to obtain lactam derivative 4.

General Procedure for the synthesis of ecdysteroid 6-oxime ethers (5-15). $200 \mathrm{mg}$ of $\mathbf{1}(0,35 \mathrm{mmol})$ was dissolved in pyridine $(8 \mathrm{ml})$, and, depending on the oxime ether to be obtained, $200 \mathrm{mg}$ of the appropriate alkoxyamine-hydrochloride was added to the solution under stirring. After stirring at $70^{\circ} \mathrm{C}$ for $24 \mathrm{~h}$, the mixture was cooled down to $0^{\circ} \mathrm{C}$, neutralized with $\mathrm{KOH}$ dissolved in anhydrous methanol, and evaporated under reduced pressure. Water $(50 \mathrm{ml})$ was then added, and the mixture was extracted with EtOAc $(3 \times 50 \mathrm{ml})$. The combined organic layers were dried with $\mathrm{Na}_{2} \mathrm{SO}_{4}$, and, after filtration, the solvent was evaporated under reduced pressure. Purification of the crude material was carried out by flash chromatography on silica gel to obtain compounds 5-15, respectively. In cases of oxime pairs $2-\mathbf{3}, \mathbf{6}-\mathbf{7}, \mathbf{8}-\mathbf{9}, \mathbf{1 4}-\mathbf{1 5}$ preparative RP-HPLC was applied to separate the isomeric oxime and oxime ether derivatives.

Compound 4: White solid; yield: $8 \%$ (11.04 mg); RP-HPLC purity: 98.1\%; for ${ }^{1} \mathrm{H}$ and ${ }^{13} \mathrm{C}$ NMR data, see Tables 2 and 3 , respectively; HR-HESI-MS: $\mathrm{C}_{33} \mathrm{H}_{52} \mathrm{O}_{6} \mathrm{~N}$, calcd. 558.3789, found: 558.3737 .

Compound 5: White solid; yield: 28.3\% (59.53 mg); RP-HPLC purity: 99.8\%; for ${ }^{1} \mathrm{H}$ and ${ }^{13} \mathrm{C}$ NMR data, see Tables 1 and 3 , respectively; HR-HESI-MS: $\mathrm{C}_{34} \mathrm{H}_{56} \mathrm{O}_{7} \mathrm{~N}$, calcd. 590.4051, found: 590.4045

Compound 6: White solid; yield: $15.2 \%$ (32.75 mg); RP-HPLC purity: 99.6\%; for ${ }^{1} \mathrm{H}$ and ${ }^{13} \mathrm{C}$ NMR data, see Tables 1 and 3 , respectively; HR-HESI-MS: $\mathrm{C}_{35} \mathrm{H}_{58} \mathrm{O}_{7} \mathrm{~N}$, calcd. 604.4208, found: 604.4198 .

Compound 7: White solid; yield: $2.8 \%$ (6.06 mg); RP-HPLC purity: 98.7\%; for ${ }^{1} \mathrm{H}$ and ${ }^{13} \mathrm{C}$ NMR data, see Tables 1 and 3, respectively; HR-HESI-MS: $\mathrm{C}_{35} \mathrm{H}_{58} \mathrm{O}_{7} \mathrm{~N}$, calcd. 604.4208, found: 604.4199 .

Compound 8: White solid; yield: $15.5 \%$ (34.05 mg); RP-HPLC purity: 98.3\%; for ${ }^{1} \mathrm{H}$ and ${ }^{13} \mathrm{C}$ NMR data, see Tables 1 and 3, respectively; HR-HESI-MS: $\mathrm{C}_{36} \mathrm{H}_{58} \mathrm{O}_{7} \mathrm{~N}$, calcd. 616.4208, found: 616.4201 .

Compound 9: White solid; yield: $1.6 \%$ (3.5 mg); RP-HPLC purity: 99.6\%; for ${ }^{1} \mathrm{H}$ and ${ }^{13} \mathrm{C}$ NMR data, see Tables 1 and 3, respectively; HR-HESI-MS: $\mathrm{C}_{36} \mathrm{H}_{58} \mathrm{O}_{7} \mathrm{~N}$, calcd. 616.4208, found: 616.4200 .

Compound 10: White solid; yield: 38.9\% (87.67 mg); RP-HPLC purity: 98.5\%; for ${ }^{1} \mathrm{H}$ and ${ }^{13} \mathrm{C}$ NMR data, see Tables 1 and 3 , respectively; HR-HESI-MS: $\mathrm{C}_{37} \mathrm{H}_{62} \mathrm{O}_{7} \mathrm{~N}$, calcd. 632.4521, found: 632.4515 .

Compound 11: White solid; yield: 43.3\% (88.32 mg); RP-HPLC purity: 97.7\%; for ${ }^{1} \mathrm{H}$ and ${ }^{13} \mathrm{C}$ NMR data, see Tables 2 and 3 , respectively; HR-HESI-MS: $\mathrm{C}_{34} \mathrm{H}_{54} \mathrm{O}_{6} \mathrm{~N}$, calcd. 572.3946, found: 572.3937.

Compound 12: White solid; yield: 33.3\% (69.59 mg); RP-HPLC purity: 97.5\%; for ${ }^{1} \mathrm{H}$ and ${ }^{13} \mathrm{C}$ NMR data, see Tables 2 and 3 , respectively; HR-HESI-MS: $\mathrm{C}_{35} \mathrm{H}_{56} \mathrm{O}_{6} \mathrm{~N}$, calcd. 586.4102, found: 586.4099 .

Compound 13: White solid; yield: $2 \%$ (4.25 mg); RP-HPLC purity: 98.3\%; for ${ }^{1} \mathrm{H}$ and ${ }^{13} \mathrm{C}$ NMR data, see Tables 2 and 3, respectively; HR-HESI-MS: $\mathrm{C}_{36} \mathrm{H}_{56} \mathrm{O}_{6} \mathrm{~N}$, calcd. 598.4102, found: 598.4094 .

Compound 14: White solid; yield: $8.3 \%$ (18.17 mg); RP-HPLC purity: 98.7\%; for ${ }^{1} \mathrm{H}$ and ${ }^{13} \mathrm{C}$ NMR data, see Tables 2 and 3 , respectively; HR-HESI-MS: $\mathrm{C}_{37} \mathrm{H}_{60} \mathrm{O}_{6} \mathrm{~N}$, calcd. 614.4415, found: 614.4411.

Compound 15: White solid; yield: $2.5 \%$ (5.48 mg); RP-HPLC purity: 95.8\%; for ${ }^{1} \mathrm{H}$ and ${ }^{13} \mathrm{C}$ NMR data, see Tables 2 and 3 , respectively; HR-HESI-MS: $\mathrm{C}_{37} \mathrm{H}_{60} \mathrm{O}_{6} \mathrm{~N}$, calcd. 614.4415, found: 614.4407.

\subsection{Biology}

Cell cultures. The human gynecological cancer cell lines MDAMB-231 and MCF7 (breast cancers), and HeLa (cervical adenocarcinoma) were purchased from ECACC (European Collection of Cell Cultures, Salisbury, UK), while SiHa (cervical carcinoma) was purchased from ATCC (American Tissue Culture Collection, Manassas, Virginia, USA). The cells were grown in Minimum Essential Medium (MEM) supplemented with $10 \%$ fetal calf serum (FCS), $1 \%$ nonessential aminoacids, and $1 \%$ penicillin-streptomycin. All media and supplements for these experiments were obtained from Lonza Group Ltd. (Basel, Switzerland). The cells were maintained at $37^{\circ} \mathrm{C}$ in humidified atmosphere containing $5 \% \mathrm{CO}_{2}$. Two mouse lymphoma cell lines were also used: a drug susceptible cell line, L5178 mouse T-cell lymphoma (ECACC catalog number 87111908, U.S. FDA, Silver Spring,MD, U.S.), and its multidrug resistant counterpart ( L5178 $_{\text {MDR }}$ ) obtained by transfection with pHa MDR1/A retrovirus [31]. Cells were cultured in McCoy's 5A media supplemented with nystatin, L-glutamine, penicillin, streptomycin, and inactivated horse serum, at $37 \circ \mathrm{C}$ and $5 \% \mathrm{CO}_{2}$. The MDR cell line was selected by culturing the infected cells with $60 \mathrm{~g} / \mathrm{L}$ colchicine (Sigma). Media, fetal bovine serum, horse serum, and antibiotics were purchased from Sigma.

Antiproliferative assay on human gynecological cancer cell lines. The growth-inhibitory activities of the prepared ecdysteroid analogs were determined by the MTT (3-(4,5-dimethylthiazol-2yl)-2,5-diphenyltetrazolium bromide) method on four human adherent cancer cell lines of gynecological origin [32]. Briefly, cells were seeded into 96 well plates (5000 cells/well) and incubated with increasing concentrations of the tested compounds $(0.1-30.0 \mu \mathrm{M})$ under cell-culturing conditions. After incubation for $72 \mathrm{~h}, 5 \mathrm{mg} / \mathrm{ml}$ MTT solution was added and the samples were incubated for another $4 \mathrm{~h}$. The precipitated formazan crystals than were dissolved in dimethyl sulfoxide and the absorbance was measured at $545 \mathrm{~nm}$ with a microplate reader. Cisplatin, a clinically used anticancer agent was used as a positive control. In order to calculate fifty percent inhibitory concentrations $\left(\mathrm{IC}_{50}\right)$, sigmoidal dose-response curves were fitted to the measured points by using the non-linear regression model log (inhibitor) vs. normalized response and variable slope with a least squares (ordinary) fit of GraphPad Prism 5.01 software (GraphPad Software Inc., San Diego, CA, USA).

Cytotoxicity assay on murine lymphoma cell lines. Cytotoxic activities on the L5178 and L5178 $8_{\text {MDR }}$ cell lines were performed as described before [18]. Briefly, $5 \times 10^{4}$ cells/well were incubated with serial dilutions of each compound $(\mathrm{n}=3)$ in McCoy's $5 \mathrm{~A}$ medium (Sigma-Aldrich) for $48 \mathrm{~h}$ at $37^{\circ} \mathrm{C}, 5 \% \mathrm{CO}_{2}$. Then, 3-(4,5dimethylthiazol-2-yl)-2,5-diphenyltetrazolium bromide (MTT, Sigma) was added to each well at a final concentration of $0.5 \mathrm{mg} / \mathrm{mL}$ per well and after $4 \mathrm{~h}$ of incubation, $100 \mu \mathrm{L}$ of sodium dodecyl sulfate (SDS) $10 \%$ (Sigma-Aldrich) in $0.01 \mathrm{M} \mathrm{HCl}$ was added to each well. Plates were further incubated overnight, the optical densities were read at 540 and $630 \mathrm{~nm}$ using an ELISA reader (Multiskan EX, Thermo Labsystem, Milford, MA, USA), and $\mathrm{IC}_{50}$ values were calculated as described above.

Rhodamine 123 accumulation assay. ABCB1 inhibitory activities of the compounds were studied through their effect on the 
accumulation of rhodamine 123 , a fluorescent dye that is an $\mathrm{ABCB} 1$ substrate. Flow cytometry was used as described before [15]. Briefly, $2 \times 10^{6}$ cells $/ \mathrm{mL}$ were treated with 2 or $20 \mu \mathrm{M}$ of each compound. After $10 \mathrm{~min}$ incubation, rhodamine 123 (SigmaAldrich) was added to a final concentration of $5.2 \mu \mathrm{M}$ and the samples were incubated at $37{ }^{\circ} \mathrm{C}$ in a water bath for $20 \mathrm{~min}$. Samples were centrifuged (Heraeus Labofuge 400, Thermo Fisher Scientific, Waltham, MA, USA) (2000 rpm, $2 \mathrm{~min})$ and washed twice with phosphate buffer saline (PBS, Sigma). The final samples were re-suspended in $0.5 \mathrm{~mL}$ PBS and its fluorescence measured with a Partec CyFlow flow cytometer (Partec, Münster, Germany). $100 \mathrm{nM}$ of tariquidar was used as positive control, which was kindly provided by Dr. Milica Pesic from the Institute for Biological Research Sinisa Stankovic, Belgrade, Serbia.

Cytotoxicity assay in combination with doxorubicin. The checkerboard microplate method was utilized to test the combined activity of doxorubicin (Teva, Budapest, Hungary) and the ecdysteroid derivatives on the $\mathrm{L} 5178$ and $\mathrm{L} 5178_{\mathrm{MDR}}$ cell lines, as described before [17]. Briefly, $5 \times 10^{4}$ cells/well were incubated with doxorubicin and the compound to be tested in McCoy's 5 A medium (Sigma-Aldrich) for $48 \mathrm{~h}$ at $37^{\circ} \mathrm{C}, 5 \% \mathrm{CO}_{2}$. Then, 3-(4,5dimethylthiazol-2-yl)-2,5-diphenyltetrazolium bromide (MTT, Sigma) was added to each well at a final concentration of $0.5 \mathrm{mg} / \mathrm{mL}$ per well, and after $4 \mathrm{~h}$ of incubation, $100 \mu \mathrm{L}$ of sodium dodecyl sulfate (SDS) $10 \%$ (Sigma-Aldrich) in $0.01 \mathrm{M} \mathrm{HCl}$ was added to each well. The plates were further incubated overnight, and the optical densities were read at 540 and $630 \mathrm{~nm}$ using an ELISA reader (Multiskan EX, Thermo Labsystem, Milford, MA, USA). The interaction was evaluated using the CompuSyn software (CompuSyn Inc., Paramus, NJ, USA) at each constant ratio of compound vs. doxorubicin $(\mathrm{M} / \mathrm{M})$, and combination index $(\mathrm{CI})$ values were obtained for $50 \%, 75 \%$, and $90 \%$ of growth inhibition. Single-drug data obtained from the duplicate control lanes of each plate were utilized to determine cytotoxic activities for each compound.

\section{Acknowledgements}

This work was performed in collaboration within the framework of COST Action CM1407 (Challenging organic syntheses inspired by nature-from natural products chemistry to drug discovery), and it was supported by the National Research, Development and Innovation Office, Hungary (NKFIH; K119770 and K109293). A.H. acknowledges the János Bolyai fellowship of the Hungarian Academy of Sciences and the Kálmán Szász Prize.

\section{Appendix A. Supplementary data}

Supplementary data related to this article can be found at https://doi.org/10.1016/j.ejmech.2017.12.032.

\section{References}

[1] I.H. Lone, K.Z. Khan, B.I. Fozdar, F. Hussain, Steroids 78 (2013) 945-950.

[2] D.P. Jindal, R. Chattopadhaya, S. Guleira, R. Gupta, Eur. J. Med. Chem. 38 (2003) 1025-1034.

[3] D.B. Garcia, R.G. Brown, J.N. Delgado, J. Pharmaceut. Sci. 69 (1980) 995-999.

[4] N.M. Krstić, M.S. Bjelaković, Z. Zizak, M.D. Pavlović, Z.D. Juranić, V.D. Pavlović, Steroids 72 (2007) 406-414.

[5] J. Cui, L. Fan, L. Huang, H. Liu, A. Zhou, Steroids 74 (2009) 62-72.

[6] J. Cui, L. Fan, Y. Huang, Y. Xin, A. Zhou, Steroids 74 (2009) 989-995.

[7] Á. Berényi, R. Minorics, Z. Iványi, I. Ocsovszki, E. Ducza, H. Thole, J. Messinger, J. Wölfling, G. Mótyán, E. Mernyák, É. Frank, G. Schneider, Steroids 78 (2013) $69-78$.

[8] R.M. Pascual, S.M. Reyes, J.L. Vega-Baez, S.M. Smith, Steroids 122 (2017) $24-33$.

[9] H.L. Qin, J. Leng, C.P. Zhang, I. Jantan, M.W. Amjab, M. Sher, M.N. Hassan, M.A. Hussain, S.N.A. Bukhari, J. Med. Chem. 59 (2016) 3549-3561.

[10] G.F. Zha, H.L. Qin, B.G.M. Youssif, M.W. Amjad, M.A.G. Raja, A.H. Abdelazeem, S.N.A. Bukharim, Eur. J. Med. Chem. 135 (2017) 34-48.

[11] L. Dinan, Phytochemistry 57 (2001) 325-339.

[12] L. Dinan, Arch. Insect Biochem. Physiol. 72 (2009) 126-141.

[13] L. Dinan, R. Lafont, J. Endocrinol. 191 (2006) 1-8.

[14] M. Báthori, N. Tóth, A. Hunyadi, Á. Márki, E. Zádor, Curr. Med. Chem. 15 (2008) 75-79.

[15] M.K. Parr, F. Bortré, A. Naß, J. Hengevoss, P. Diel, G. Wolber, Biol. Sport 32 (2015) 169-173.

[16] R. Lafont, L. Dinan, J. Insect Sci. 3 (7) (2003) 1-30.

[17] A. Martins, N. Tóth, A. Ványolós, Z. Béni, I. Zupkó, J. Molnár, M. Báthori, A. Hunyadi, J. Med. Chem. 55 (2012) 5034-5043.

[18] A. Martins, P. Sipos, K. Dér, J. Csábi, W. Miklós, W. Berger, A. Zalatnai, L. Amaral, J. Molnár, P. Szabó-Révész, A. Hunyadi, BioMed Res. Int. (2015), 895360.

[19] A. Martins, J. Csábi, A. Balázs, D. Kitka, L. Amaral, J. Molnár, A. Simon, G. Tóth, A. Hunyadi, Molecules 55 (2013) 15255-15275.

[20] A. Hunyadi, J. Csábi, A. Martins, J. Molnár, A. Balázs, G. Tóth, Molecules 22 (2017) 199.

[21] J. Csábi, A. Martins, I. Sinka, A. Csorba, J. Molnár, I. Zupkó, G. Tóth, L.M.V. Tillekeratne, A. Hunyadi, Med. Chem. Commun. 7 (2016) 2282-2289.

[22] I.V. Galyautdinov, N.A. Ves'kina, S.R. Afon'kina, L.M. Khalilov, V.N. Odinokov, Russ. J. Org. Chem. 42 (2006) 1352-1357.

[23] R.V. Shafikov, Ya. R. Urazaeva, S.R. Afon'kina, R.G. Savchenko, L.M. Khalilov, V.N. Odinokov, Russ. J. Org. Chem. 45 (2009) 1456-1463.

[24] A. Balázs, A. Hunyadi, J. Csábi, N. Jedlinszki, A. Martins, A. Simon, G. Tóth, Magn. Reson. Chem. 51 (2013) 830-836.

[25] T.C. Chou, Pharmacol. Rev. 58 (2006) 621-681.

[26] S. Marchetti, R. Mazzanti, J.H. Beijnen, J.H.M. Schellens, Oncologist 12 (2007) 927-941.

[27] R. Callaghan, F. Luk, M. Bebawy, Drug Metabol. Dispos. 42 (2014) 623-631.

[28] E. Pretsch, T. Clerc, J. Seibl, W. Simon, Structuraufklaerung Organischer Verbindungen, Springer-Verlag, Berlin, Germany, 1976. C10, C175, C195.

[29] H. Duddeck, W. Dietrich, G. Tóth, Structure Elucidation by Modern NMR, Springer-Steinkopff, Darmstadt, Germany, 1998.

[30] E. Pretsch, G. Tóth, M.E. Munk, M. Badertscher, Computer-aided Structure Elucidation. Spectra Interpretation and Structure Generation, Wiley-VCH, Weinheim, Germany, 2002.

[31] I. Pastan, M.M. Gottesman, K. Ueda, E. Lovelace, A.V. Rutherford, M.C. Willingham, Proc. Nat. Acad. Sci. U. S. Am. 85 (1988) 4486-4490.

[32] T. Mosmann, J. Immunol. Meth. 65 (1983) 55-63. 